\title{
Treatment of early uterine sarcomas: disentangling adjuvant modalities
}

\author{
Flora Zagouri ${ }^{1}$, Athanasios-Meletios Dimopoulos ${ }^{1}$, Stelios Fotiou ${ }^{2}$, \\ Vassilios Kouloulias ${ }^{3}$ and Christos A Papadimitriou*1
}

\begin{abstract}
Address: ${ }^{1}$ Department of Clinical Therapeutics, "Alexandra" Hospital, University of Athens, School of Medicine, Athens, Greece, ${ }^{2}$ Aretaieion Hospital, University of Athens, School of Medicine, Athens, Greece and ${ }^{3}$ Attikon Hospital, University of Athens, School of Medicine, Athens, Greece
\end{abstract}

Email: Flora Zagouri - florazagouri@yahoo.co.uk; Athanasios-Meletios Dimopoulos - mdimop@med.uoa.gr; Stelios Fotiou - sfotiou@yahoo.gr; Vassilios Kouloulias - vkoul@yahoo.gr; Christos A Papadimitriou* - chr_papadim@yahoo.gr

* Corresponding author

Published: 8 April 2009

World Journal of Surgical Oncology 2009, 7:38 doi:10.1186/1477-7819-7-38

This article is available from: http://www.wjso.com/content/7/I/38

(c) 2009 Zagouri et al; licensee BioMed Central Ltd.

This is an Open Access article distributed under the terms of the Creative Commons Attribution License (http://creativecommons.org/licenses/by/2.0), which permits unrestricted use, distribution, and reproduction in any medium, provided the original work is properly cited.

\begin{abstract}
Uterine sarcomas are a rare group of neoplasms with aggressive clinical course and poor prognosis. They are classified into four main histological subtypes in order of decreasing incidence: carcinosarcomas, leiomyosarcomas, endometrial stromal sarcomas and "other" sarcomas. The pathological subtype demands a tailored approach. Surgical resection is regarded as the mainstay of treatment. Total abdominal hysterectomy and bilateral salpingo-oophorectomy represents the standard treatment of uterine sarcomas. Pelvic and para-aortic lymph node dissection in carcinosarcomas is recommended, given their high incidence of lymph node metastases, and may have a role in endometrial stromal sarcomas. Adjuvant radiation therapy has historically been of little survival value, but it appears to improve local control and may delay recurrence. Regarding adjuvant chemotherapy, there is little evidence in the literature supporting its use except for carcinosarcomas. However, more trials are needed to address these issues, especially, their sequential application. Patients with uterine sarcomas should be referred to large academic centers for participation in clinical trials.
\end{abstract}

\section{Background}

Uterine sarcomas are rare neoplasms comprising $1 \%$ of all gynaecologic malignancies and $4-9 \%$ of all malignant uterine neoplasms $[1,2]$. It is estimated that the incidence of uterine sarcomas varies between 0.5 and 3.3 cases per 100.000 females per year [3]. Uterine sarcomas usually display aggressive clinical behaviour, with a great tendency to local recurrence and even greater to distant spread [4-7]. Due to their low incidence and the fact that they lack a preinvasive stage, there is no established practice for screening these tumours. The rarity of uterine sar- comas and their often aggressive clinical course has resulted in a relatively limited amount of literature.

The staging of uterine sarcomas is based on the International Federation of Gynecology and Obstetrics staging system for uterine corpus cancer. According to WHO classification, uterine sarcomas are classified into four main histological subtypes in order of decreasing incidence: carcinocarcomas, leiomyosarcomas, endometrial stromal sarcomas and "other" sarcomas [8]. Unfortunately, clinical-trial reports and literature reviews often include a 
broad range of histological subtypes of sarcoma, which restricts interpretation and application of results. Response rates from protocols with multiple subtypes should consequently be interpreted with caution. Therefore, the effort to tailor the approach to patients with uterine sarcomas by pathological subtype seems mandatory.

\section{Carcinosarcomas (CSs) Epidemiology and Tumour Features}

Carcinosarcomas represent a highly aggressive subtype of uterine malignancy [9-12]. CSs comprise both malignant epithelial and malignant sarcomatous components [1315]. The differentiation of the epithelial component is usually glandular with the endometrioid adenocarcinoma being the most common epithelial type. The mesenchymal components may be "homologous", similar to tissues normally present in the uterus, or "heterologous, " resembling tissue foreign to the uterus [12-15]. Patients with CSs usually present with a bulky polypoid mass extending into and even through the endocervical canal $[16,17]$.

The recurrence rate for stage I and II CSs is approximately $50 \%[12,18]$. Unfortunately, patients who present with early-stage disease confined to the uterus have a 2- to 5-year overall survival of approximately 50\% (reviewed by Kanjeekal et al [19]). Factors associated with poor prognosis include stage, high grade of tumour, adnexal spread and lymph node metastasis. The prognostic relevance of histopathological variables, the grade of sarcomatous and epithelial component, the mitotic count of sarcomatous component, as well as the depth of myometrial invasion, the lymph-vascular space involvement and peritoneal cytology have been implicated in some studies as significant pathologic predictors [10,11,20-23]. It should, however, be noted that these findings did not emerge in the majority of studies conducted. Notwithstanding, the limited number of patients and the fact that most studies are not stratified for stage do not allow definitive conclusions to be drawn.

\section{Surgical Treatment}

Surgical treatment of CSs should comprise exploratory laparotomy, total abdominal hysterectomy (TAH), bilateral salpingo-oophorectomy (BSO), omentectomy, aspiration of abdominal fluid for cytologic evaluation, pelvic and para-aortic lymph node dissection and tumor debulking at the time of presentation $[12,13,16,17,19,24]$. Lymph node dissection is indicated for CSs given their high incidence of lymph node metastases $[18,25,26]$. Moreover, the number of lymph nodes collected in stage I-II patients, who underwent pelvic and para-aortic lymph node sampling, has been correlated with the risk of recurrence and survival $[25,26]$. Surgical debulking in patients with uterine CSs should be attempted, given that patients with minimal residual disease may have a longer survival than those left with gross residual disease after surgical debulking [12]. More accurate surgical staging of CSs, as with endometrial cancer, may allow physicians to better assess the need for adjuvant treatment.

\section{Radiation Therapy}

Historically, treatment for uterine CSs has included adjuvant pelvic radiation therapy with or without brachytherapy [12]. Until 2007, no well-controlled, randomized studies had been published, and most reports were based on small non-randomized trials [26-28]. The best conclusion that could be drawn from these reports was that the routine place of adjuvant pelvic radiation was limited as it only led to a statistically significant reduction of recurrences within the radiation field, but did not confer to overall survival [26-29]. Nonetheless, adjuvant radiotherapy has been shown to improve survival for patients with early-stage CSs who had not undergone lymph node dissection $[29,30]$.

In their retrospective analysis, Callister et al [31] found that patients treated with pelvic irradiation had a lower rate of pelvic recurrence than those treated with surgery alone ( $28 \%$ versus $48 \%, p=0.0002$ ), but the 5 -year overall survival and distant metastasis rates were not significantly different. Interestingly, patients treated with pelvic irradiation had a longer median time to any distant relapse (17.3 versus. 7.0 months, $\mathrm{p}=0.001$ ) than those treated with surgery alone. In another retrospective analysis of 2461 women with uterine CSs within the SEER (Surveillance, Epidemiology, and End results program) database of the US National Cancer Institute, radiation therapy predicted an improved overall and disease specific survival [32]. Five-year overall survival rates were $41.5 \%$ and $33.2 \%(\mathrm{p}<0.001)$ for women receiving or not irradiation, respectively. More analytically, women with stage I-III disease experienced a benefit in overall survival (hazard ratio $=0.87, \mathrm{p}=0.03$ ), while those with stage IV disease experienced benefit in both overall $(\mathrm{HR}=0.63, \mathrm{p}<0.001)$ and uterine-specific survival $(\mathrm{HR}=0.63, \mathrm{p}=0.004)$.

In 2007, GOG published the results of a randomized phase III study which compared patient outcome following treatment with adjuvant whole abdominal irradiation (WAI) versus chemotherapy with three cycles of cisplatin and ifosfamide (CIM) for patients with CS. Eligible patients had stage I-IV disease, no more than $1 \mathrm{~cm}$ postsurgical residuum and/or no extra-abdominal spread. FIGO stage was I+II in $44 \%$ of the enrolled, eligible women. Adjusting for stage and age, the recurrence rate was $21 \%$ lower for CIM patients than for WAI patients (relative hazard $=0.789, \mathrm{p}=$ 0.245 ). The estimated death rate was $29 \%$ lower among the CIM group (relative hazard $=0.712, \mathrm{p}=0.085$ ). Although the observed differences were not statistically significant, the authors seems to favor the use of combination chemotherapy in future trials [33]. 
In the mid-1980s, the European Organisation for Research and Treatment of Cancer (EORTC) Gynaecological Cancer Group proposed a trial to evaluate adjuvant radiotherapy in stage I+II uterine sarcomas (protocol 55874). The study opened in 1987 taking 13 years to accrue 224 patients and its results were first published in 2008. Patients were required to have undergone as a minimum, TAH and BSO and washings, but nodal sampling was optional. There were 103 LMSs, 91 CSs and 28 ESSs. Patients were randomised to either observation or pelvic radiation, $51 \mathrm{~Gy}$ in 28 fractions over 5 weeks. Analysis for all patients revealed a reduction in local relapse $(\mathrm{p}=$ 0.004 ), but no effect on either OS or PFS. Furthermore, no difference in either overall or disease-free survival was demonstrated among CS patients but there was an increased local control for those receiving radiation, while this benefit was not observed for women with LMSs. Prognostic factor analysis showed that stage, age and histological subtype were important predictors of behaviour [34].

In conclusion, CSs appears to behave like poorly differentiated endometrial carcinomas. Offering adjuvant pelvic radiation applies only to patients that have not undergone a complete surgical staging including lymph node staging. However, further randomized trials are necessary in order to clarify the exact role of adjuvant radiotherapy, especially in combination with platinum-based chemotherapy.

\section{Chemotherapy}

The role of adjuvant chemotherapy in CSs is still under debate. In a prospective phase II GOG study, patients with completely resected stage I or II CSs received three cycles of adjuvant chemotherapy with ifosfamide and cisplatin. PFS and OS, respectively, were $54 \%$ and $52 \%$ at 84 months. The authors concluded that the impact of adjuvant ifosfamide and cisplatin on survival outcomes was unclear, while pelvic relapses remained a concern [35]. In a recently published retrospective analysis, 49 women with completely resected stage I-IV CSs received in the adjuvant setting either platinum-based chemotherapy with or without radiation therapy (pelvic or WAI), or radiation therapy alone. Three-year PFS for chemotherapy group (with or without radiation therapy) was 35\% versus $9 \%$ for radiation therapy alone $(\mathrm{HR}=1.74, \mathrm{p}=0.164)$, while the corresponding 3 -year OS rates were $66 \%$ and $34 \%$, respectively $(\mathrm{HR}=$ $2.02, \mathrm{p}=0.146)$. Interestingly, the majority of patients in the chemotherapy group were treated with paclitaxel and carboplatin [36]. When compared with other regimens, the latter combination seems also to improve the overall survival rate of patients with ovarian CSs [37].

\section{Endocrine therapy}

In contrast to ESS, endocrine therapy has no place in the adjuvant treatment of CS. However, given that apparently $30 \%$ of these tumours express estrogen and/or progesterone receptors, hormone therapy may represent an option in chemotherapy pretreated patients with hormone receptor positive tumours [12].

\section{Leiomyosarcomas (LMSs) Epidemiology and Tumour Features}

Smooth muscle cell tumours may be divided into three groups: benign (leiomyoma), malignant (leiomyosarcoma), and tumours of unknown malignant potential [38]. Uterine LMS is a rare tumour, accounting for approximately $1 \%$ of all uterine malignancies, and represents the second more common uterine sarcoma. According to an analysis of SEER program data, CS were the most common uterine sarcoma followed by LMS [3,12,39]. The incidence of LMS in patients operated for presumed leiomyoma is approximately $0.1-0.3 \%$ [40]. Unfortunately, due to the stromal rather than endometrial origin of the tumour, LMS is not often diagnosed preoperatively. Although some patients complain of pain or bleeding and undergo endometrial biopsy as a result of these symptoms, most women with LMS lack symptoms, while others present with a rapidly enlarging pelvic mass and thus do not undergo biopsy before surgery $[12,16,17]$.

Sixty percent of women with LMS present with disease clinically limited to the uterus. Cure rates for these patients range from $20 \%$ to $60 \%$, with rates depending on the success of primary resection $[12,13]$. The recurrence rate is approximately $70 \%$ for stage I and II disease, and the site of recurrence is often distant $[12,18]$. Favourable prognostic features to emerge in some studies include premenopausal status, low mitotic count, pushing margins, hyalinization, absence of necrosis, origin in a uterine leiomyoma, and tumour stage. However other studies question these findings [18,41-43]. The main criteria used to determine treatment and prognosis are: necrosis, nuclear atypia, and mitotic count $[12,41,43]$.

\section{Surgical Treatment}

Management practice varies for uterine LMS, and is poorly supported by evidence in the current literature, but total abdominal hysterectomy and bilateral salpingooophorectomy is considered to be the standard surgical treatment $[4,12,13,16,44]$. Contrary to CS, pelvic and/or para-aortic lymphadenectomy is not indicated for LMS, unless macroscopic extra-uterine disease is present; due to the low rates of negative nodes and the fact that the dominant pattern of recurrence in LMS is outside the pelvis and the abdominal cavity $[13,16,17,44]$.

Ovarian preservation may be considered in premenopausal patients with early-stage leiomyosarcoma of the uterus as case-control investigations suggest that it does not adversely affect survival $[13,44]$. In a retrospective review of 208 patients with LMS of the uterine, the multivariate analysis showed that oophorectomy was associated with a significantly worse disease-specific survival [44]. 


\section{Radiation therapy}

Pelvic radiation therapy has been used for adjuvant treatment of uterine LMS. However, although radiation therapy has been shown to reduce the pelvic relapse rate by $50 \%$, studies have not demonstrated a significant survival benefit with this approach $[12,27,31,44-46]$. The results of the protocol 55874 coincide with this observation. This significant randomized trial demonstrated that patients with LMS did not show the same benefit from radiation as patients with CSs [34].

In patients with LMS, in contrast to patients with other uterine sarcomas, the dominant pattern of recurrence is outside the pelvis and abdominal cavity [47-49]. At least two thirds of patients with uterine LMS have some component of distant disease at first recurrence. Thus, although the rate of recurrence in the pelvis is not insubstantial, little is potentially gained by delivering pelvic radiation as a postoperative adjuvant treatment.

\section{Chemotherapy}

No adjuvant treatment has been shown to improve survival, although prospective data are very limited. However, in a small phase II study, four cycles of adjuvant chemotherapy with gemcitabine and docetaxel in patients with completely resected stage I-IV, high-grade uterine LMSs resulted in 2-year PFS rates that appear superior to historical rates (this issue will be discussed more detailed in the final section of the article) [50].

\section{Endocrine therapy}

Endocrine therapy has no place in the adjuvant treatment of patients with LMS.

\section{Endometrial Stromal Sarcoma (ESSs) Epidemiology and Tumour Features}

ESS is a rare entity of uterine malignancy, accounting for $0.2-1 \%$ of all uterine malignancies and $6-20 \%$ of all uterine sarcomas [51-53]. Due to its rarity, ESS has only been reported in a few studies, and these were limited to case reports or retrospective analysis based on a small number of patients. These tumours are most commonly seen in premenopausal women, but age at presentation may range from 20 to 80 years [12]. Patients typically present with bleeding and pain $[17,54]$. Due to the fact that most patients with ESS have obvious symptoms, they are usually diagnosed at an early stage [54-56].

According to its pathological features ESS has been classified as low grade or high grade $[12,55]$. Low-grade ESS is characterized by fewer than 10 mitoses per 10 high-power fields and a lack of significant atypia and often expresses estrogen and progesterone receptors. It should be noted that nowadays, rather than including high-grade ESSs in the category of ESSs, they are grouped together with highgrade or undifferentiated uterine sarcomas (UUSs). This is important because the low-grade and high-grade variants have vastly different prognostic factors and therapeutic options [54-56].

ESS may arise from uterine stroma, adenomyosis, or possibly endometriosis [12,57]. They usually have an indolent clinical course with 5 -year survival rates of $80 \%$ to almost $100 \%$, but about $37-60 \%$ of patients eventually recur after a very long time and $15-25 \%$ die of the disease [13]. In ESS recurrences are usually local, but late recurrences may involve the lung and abdomen. Stage at presentation is the best predictor of recurrence risk [12].

ESSs frequently show positive immunoreactivity for ER and PR, which helps in differential diagnosis [57-68]. Reich et al [63], analysed ER and PR expression in a retrospective series of 21 patients with ESS. ER and PR were measured with monoclonal antibodies and the peroxidase-antiperoxidase method and a score was calculated, as for breast carcinoma, based on both the percentage of positive tumour cell nuclei and the staining intensity. The authors concluded that ER and PR expression in ESSs is heterogeneous. This finding may have implications for hormone therapy in the management of these tumours and may suggest that ER and PR should be routinely quantified in ESSs by immunohistochemical methods. Chu et al [62] evaluated the expression of ER-alpha and ER-beta in low grade ESS and they suggested that loss of ER $\beta$ expression may be a marker for malignancy. Accordingly, Balleine et al [59] showed that PR isoform expression, similarly to that of a normal endometrial stroma, is consistent with the highly differentiated phenotype of this tumor and that variant differentiation or disease recurrence was accompanied by an altered $\mathrm{PR}$ isoform profile that could impact on hormone response.

\section{Surgical Treatment}

Surgical treatment of ESS typically includes an exploratory laparotomy, total abdominal hysterectomy and bilateral salpingo-oophorectomy, omental biopsy, and aspiration of abdominal fluid for cytologic evaluation $[7,12,13,54,69,70]$. If the tumour is palpable in the parametrium, a more extensive procedure, such as a radical hysterectomy, should be performed [12]. Lymph node sampling is not the standard of care, as nodal involvement by low-grade ESS is supposed to be rare [12]. In two recently published series nodal involvement was found in $33-45 \%$ of cases during primary or secondary surgical treatment, and lymphadenectomy has been suggested by the authors as part of the surgical treatment [71,72]. However, this finding was observed in patients with more advanced disease and, therefore, the role of lymphadenectomy in early stages still remains controversial. Ovarian ablation is necessary, as part of primary treatment, because estrogens may act as a trophic agent for these tumours [73]. 


\section{Radiation therapy}

Adjuvant radiation therapy is effective treatment for patients with ESS due to excellent local control in all stages and good disease-specific survival in early stages $[69,70]$. Adjuvant radiation therapy clearly reduces the incidence of pelvic recurrence; however, in the majority of the studies conducted it has no effect on OS [70,74-77].

\section{Chemotherapy}

See the final section of this review.

\section{Endocrine therapy}

Low-grade endometrial stromal sarcomas are estrogen and progesterone receptor positive tumors $[63,78]$. In the past, hormonal therapy consisted of progestins for advanced, recurrent or metastatic low-grade ESS. Medroxyprogesterone acetate (MPA) and megestrole acetate are synthetic derivatives of progesterone that exert their activity after binding to the progesterone receptor [79]. Aromatase inhibitors [8083] and GnRH analogues [84-86] have become new effective alternatives for first and second line treatment. The high recurrence rates after short disease free intervals in low-grade ESS patients were partly due to inadvertent growth stimulation during estrogen-containing hormone replacement therapy and tamoxifen treatment, which are contraindicated $[73,78,87]$. Recently, hormonal therapy has been introduced for the prevention of recurrences. However, it should be noted that well controlled randomised studies on ESSs have not been conducted and the majority of the results reported are based on small series.

\section{Undifferentiated Uterine Sarcomas (UUSs) Epidemiology and Tumour Features}

Undifferentiated uterine sarcomas are high-grade epithelioid or spindle cell sarcomas that cannot be classified into one of the standard categories [4,13,35]. These tumours usually present with abdominal or pelvic pain in postmenopausal women and represent less than $5 \%$ of all uterine sarcomas [12]. They are characterized by an aggressive clinical behaviour, with a tendency to frequent and early recurrences and with 5-year survival rates of 25$55 \%[7,13,52]$. Necrosis is a common finding $[12,52]$. The stage at diagnosis as well as the mitotic index have emerged in some studies as the most significant predictor of prognosis [12,52], a finding that has not been reported in other series [88].

\section{Surgical Treatment}

The treatment of choice for undifferentiated uterine sarcomas is total abdominal hysterectomy and bilateral salpingo-oophorectomy $[12,13,17,19,24]$. There are no data in the literature to support or challenge lymph node dissection. While Gaducci et al [13] suggest that this surgical procedure is not advisable, Ramondetta et al [12] recommend lymph node dissection in order to determine the risk of recurrence.

\section{Radiation therapy}

Radiation therapy is typically recommended for stage I and II UUSs $[12,13,30]$. However, concern regarding distant recurrences has led to the consideration of combining irradiation with chemotherapy.

\section{Endocrine therapy}

Hormonal therapy plays no role for UUSs due to the lack of steroid receptor expression.

\section{Overview of adjuvant chemotherapy in early stage uterine sarcomas Older non-platinum containing regimens}

The high incidence of distal metastasis in uterine sarcomas makes adjuvant chemotherapy an appealing option. Although adjuvant chemotherapy has been studied in a number of trials, considerable controversy still surrounds its use. The question is whether or not adjuvant chemotherapy can achieve a significant increase in disease-free and overall survival without major treatment-related toxicity. It should be noted, that due to the rarity of uterine sarcomas, very few prospective randomized studies have been conducted. Also, the non randomised clinical-trial reports often include a broad range of histological subtypes, which restricts interpretation and application of results.

The role of adjuvant chemotherapy and its type still remains unclear even for adult soft tissue sarcomas (STSs). The EORTC randomised patients with completely resected STSs to receive either the CyVADIC regimen (cyclophosphamide, vincristine, doxorubicin and dacarbazine) adjuvantly or no additional treatment [89]. With a median follow-up duration of 80 months, the 7-year relapse-free survival was higher and the local recurrence rate lower in the chemotherapy arm. Overall survival and the rates of distant metastases were not affected by chemotherapy. In contrast, in another randomized trial, Frustaci et al [90] demonstrated that 5 cycles of adjuvant chemotherapy with epirubicin and ifosfamide) significantly improved median disease-free (48 months versus 16 months, $\mathrm{p}=$ 0.04 ) and overall survival (75 months versus 46 months, $\mathrm{p}=0.03$ ) in patients with high-risk extremity STSs. An update of the study showed the 5-year overall survival estimate to be $66 \%$ and $46 \%(\mathrm{p}=0.04)$ for the chemotherapy and control arm, respectively [91]. The Cochrane Review performed a meta-analysis of 14 trials of adjuvant chemotherapy, involving 1568 patients with STSs. According to this meta-analysis chemotherapy improved the local recurrence-free interval $(\mathrm{HR}=0.73)$, distant recurrencefree interval $(\mathrm{HR}=0.70)$, and overall recurrence-free interval $(H R=0.75)$. The doxorubicin-based therapy yielded an advantage in terms of overall survival, but failed to achieve statistical significance $(\mathrm{HR}=0.89)$ [92].

Although uterine sarcomas are different from STSs of the trunk and extremities, in terms of pathogenesis and biolog- 
Table I: Summary of studies on adjuvant chemotherapy in early-stage uterine sarcomas.

\begin{tabular}{|c|c|c|c|c|c|}
\hline Study & No of patients & Radiation & Regimens & $\begin{array}{c}\text { Recurrence (\%) at } 5 \\
\text { years }\end{array}$ & 5-year survival (\%) \\
\hline Buchsbaum et al, 1979 [94] & 8 & NR & VAC & 37 & 63 \\
\hline Omura et al, 1985 [100] & 64 & No & DOX & 39 & 53 \\
\hline van Nagel et al, 1986 [95] & 7 & No & VAC & 29 & 86 \\
\hline Berchuck et al, 1988 [6] & 12 LMS & Yes & Various & 83 & 42 \\
\hline Piver et al, 1988 [105] & 11 & No & CyVADIC & 18 & 89 \\
\hline Hempling et al, 1995 [96] & 20 & No & CyVADIC & 35 & 68 \\
\hline Resnik et al, I995 [I0I] & $23 \mathrm{CS}$ & No & Etoposide + cisplatin + DOX & 22 & 92 (at 2 years) \\
\hline Gadducci et al, 1996 [43] & II LMS & 2 patients & Various & 39 & NR \\
\hline Sartori et al, 1997 [106] & $5 \mathrm{CS}$ & No & NR & 40 & NR \\
\hline Chauveinc et al, 1999 [21] & 24 & Yes & Various & NR & NR \\
\hline Kushner et al, 2000 [98] & 10 & No & IFO & 50 & 67 (at 3 years) \\
\hline Manolitsas et al, 200I [102] & $21 \mathrm{CS}$ & Yes & various & 9.5 & 95 \\
\hline Giuntoli et al, 2003 [44] & 34 LMS & 2 patients & Various & NR & NR \\
\hline Pautier et al, 2004 [99] & 16 & Yes & API & 28 & 100 \\
\hline Odunsi et al, 2004 [97] & 24 & No & CyVADIC & 33 & 75 \\
\hline Sutton et al, 2005 [35] & $65 \mathrm{CS}$ & No & IFO + Cisplatin & 35 & 62 \\
\hline Ti et al, $2006[104]$ & 51 & Yes & various & 59 & 67 \\
\hline Papadimitriou et al, 2007 [4] & 31 & 12 patients & Anthracycline-based & 39 & 54 \\
\hline Wolfson et al, 2007 [33] & $101 \mathrm{CS}$ & No & CIM & 52 & 46 \\
\hline
\end{tabular}

ical behavior, and results of adjuvant chemotherapy in early stage STSs cannot be extrapolated in uterine sarcomas, some studies used either the VAC or the CyVADIC combination in the adjuvant setting. More specifically, in a retrospective analysis of stage I and II uterine sarcomas, Buschbaum et al [93] reported recurrent disease in 37\% of patients who received adjuvant chemotherapy with the vincristine, dactinomycin and cyclophosphamide (VAC) regimen. In another study, Hannigan et al [94] retrospectively analyzed the outcome of patients who received after hysterectomy and radiotherapy VAC regimen or the combination of vincristine, doxorubicin and cyclophosphamide and concluded that neither the probability of survival nor the disease-free interval was improved by the addition of adjuvant chemotherapy. Adjuvant VAC was also utilized in a prospective, pilot study in patients with stage I uterine sarcomas. The authors reported that recurrence rate was significantly $(\mathrm{p}<0.02)$ less than that for patients treated by surgery alone or by surgery plus radiation [95].

The impact of adjuvant CyVADIC on survival outcomes of patients with stage I uterine sarcomas was examined in two small prospective studies. Hempling et al [96], treated twenty women who underwent total abdominal hysterectomy and bilateral salpingo-oophorectomy with this multiagent chemotherapy regimen, but failed to show a significant impact on long-term survival in this group of patients. Progression-free survival for the entire population at 2 years was $80 \%$ and at 5 years $65 \%$, while recurrence rates for pure sarcomas and carcinosarcomas did not differ significantly. In a more recently published study, Odunsi et al [97] reported results on adjuvant CyVADIC in 24 patients with a very long duration of follow-up. The estimated survival rate for the whole group was 88,75 , and $69 \%$ at 2, 5, and 15 years, respectively. Factors that did not affect survival included age, histology, and tumor grade. Based on their data, the authors suggested that CyVADIC may have a potential role in the adjuvant treatment of early-stage uterine sarcoma.

\section{Ifosfamide-containing regimens}

Ifosfamide-based chemotherapy has been investigated in the adjuvant setting in three prospective, non-randomized trials. Kushner et al [98], treated patients with completely resected moderate-to-high grade uterine sarcomas with three cycles of adjuvant ifosfamide $\left(1.5 \mathrm{~g} / \mathrm{m}^{2} /\right.$ day $\times 3$ consecutive days, repeated every 4 weeks). Median progression-free survival was 26 months with a corresponding 2year rate of $60 \%$. The 2 -year overall survival rate was $100 \%$, dropping to $64 \%$ at three years. In another French study conducted by Pautier et al [99], patients received three cycles of adjuvant chemotherapy with doxorubicin, cisplatin and ifosfamide (API) followed by radiotherapy. When compared to a group of patients treated with adjuvant radiotherapy alone, the 3-year disease-free survival was $43 \%$ in the radiotherapy group and $76 \%$ in the combined modality group. Of note, the two previously mentioned studies included a mixture of different histological types. On the contrary, only patients with CS were included in a prospective phase II GOG study, which utilized the combination of ifosfamide and cisplatin for stage I+II disease. Ifosfamide was administered $1.5 \mathrm{~g} / \mathrm{m}^{2}$, intravenously over $1 \mathrm{~h}$, and cisplatin was given $20 \mathrm{mg} / \mathrm{m}^{2}$ followed by ifosfamide $1.5 \mathrm{~g} / \mathrm{m}^{2} / 24 \mathrm{~h}$ as a continuous infusion (daily $\times 5$, every 21 days, $\times 3$ cycles). PFS and OS, respectively, were $69 \%$ and $82 \%$ at 24 months, and $54 \%$ 
and $52 \%$ at 84 months. Leukopenia was the most commonly reported, but manageable, toxicity. The authors concluded that the impact of adjuvant ifosfamide and cisplatin on survival outcomes was unclear, while pelvic relapses remained a concern [35]. In contrast, in their retrospective analysis of 31 patients with stage I or II uterine sarcomas of various histologies, Papadimitriou et al [4] found that adjuvant ifosfamide-containing chemotherapy resulted in statistically longer OS when compared with non-ifosfamide-containing chemotherapy.

The combination of ifosfamide (with MESNA uroprotection) and cisplatin (CIM regimen) was also used in a randomized phase III GOG study that enrolled 232 patients. This trial was designed to compare patient outcome following adjuvant treatment with WAI versus chemotherapy with three cycles of CIM in women with completely resected CSs. Adjusting for stage and age, the recurrence rate was 21\% lower for CIM patients than for WAI patients (relative hazard $=0.789, \mathrm{p}=$ 0.245 ). The estimated death rate was $29 \%$ lower among the CIM group (relative hazard $=0.712, \mathrm{p}=0.085$ ) [33].

\section{Anthracycline-based chemotherapy}

The role of adjuvant doxorubicin has been examined in a randomized GOG trial. After hysterectomy, 156 evaluable patients with stage I or stage II uterine sarcomas were randomly assigned to chemotherapy with doxorubicin for six months or to no further treatment. Pelvic irradiation (external or intracavitary) was optional before randomization. Of 75 patients receiving doxorubicin, 31 have suffered recurrences compared with 43 of 81 receiving no adjuvant chemotherapy, but this difference was not statistically significant. Moreover, there was no difference in progression-free interval or survival. The optional radiotherapy did not influence the outcome although there was a suggestion that vaginal recurrence was decreased by pelvic radiotherapy. The recurrence rates in specific histologies were not significantly different [100].

Anthracycline-based combinations have been used in CSs. In a phase II trial, 42 consecutive patients were treated with a combination containing etoposide $100 \mathrm{mg} / \mathrm{m}^{2}$, on days 1 and 2 , cisplatin $50 \mathrm{mg} / \mathrm{m}^{2}$ on day 1 , and doxorubicin 50 $\mathrm{mg} / \mathrm{m}^{2}$ on day 1 , repeated every 28 days. There were 23 patients with early-stage disease and 19 patients with advanced or recurrent disease. Among patients with stages I and II there were 5 (22\%) recurrences and the 2-year overall survival rate was $92 \%$ [101]. Additionally, a sequential approach with adjuvant radiation therapy and chemotherapy has been correlated with improved clinical outcome. In a pilot study, conducted by Manolitsas et al [102], patients with stage I or II uterine CSs received after surgery tailored radiation therapy and chemotherapy, consisting of cisplatin and epirubicin. The survival rate for those patients who completed treatment according to the multimodality protocol was $95 \%$, with a disease-free survival rate of $90 \%$.

\section{Newer agents and combinations}

The combination of gemcitabine and docetaxel has shown promising results as adjuvant chemotherapy for completely resected stages I-IV high grade uterine LMSs. As previously mentioned, Hensley et al [50] treated 25 patients with gemcitabine $900 \mathrm{mg} / \mathrm{m}^{2}$, on days 1 and 8 , plus docetaxel $75 \mathrm{mg} / \mathrm{m}^{2}$, on day 8 , every 3 weeks for 4 cycles. With a median follow-up of 49 months for all patients, 10 (45\%) remained progression-free at 2 years, with a median progression-free survival of 13 months. Among the 18 patients with stages I or II disease, 59\% remained progression-free at 2 years, with a median progression-free survival of 39 months. Median overall survival for these patients was not yet reached.

Another combination that merits further evaluation in the adjuvant setting, especially for patients with CSs, is the paclitaxel and carboplatin doublet. In a retrospective analysis, 49 women with completely resected stage I-IV CSs received adjuvantly either platinum-based chemotherapy (primarily paclitaxel and carboplatin) with or without radiation therapy or radiation therapy alone. Three-year PFS for chemotherapy group (with or without radiation therapy) was 35\% versus $9 \%$ for radiation therapy alone, while the corresponding 3-year OS rates were 66\% and $34 \%$, respectively $(\mathrm{HR}=2.02, \mathrm{p}=0.146)$ [36]. Furthermore, in a retrospective analysis of 26 patients with ovarian CSs, there was a trend for increased median survival for those who were treated with the paclitaxel and carboplatin combination $(\mathrm{p}=0.066)$ [37].

More recently, trabectedin, an agent that binds to the DNA minor groove and has an original mechanism of action involving proteins of the nucleotide excision repair machinery has shown promising activity in patients with advanced STSs. Several trabectedin-based combinations have been tested in phase I trials, including combination with cisplatin, paclitaxel, docetaxel and pegylated doxorubicin [103]. Based on biological and/or histological features, trabectedin will be possibly utilized in the adjuvant setting in STSs, including uterine sarcomas.

The main studies conducted on adjuvant setting of early stage uterine sarcomas are presented in Table $1[4,6,21,33,35,43,44,94-102,104-106]$.

\section{Conclusion}

Uterine sarcomas represent a heterogeneous group of rare tumours that usually have an aggressive clinical behaviour and a poor prognosis. Newer classifications will help to distinguish the different types as we now recognise that carcinosarcomas are most likely to be of epithelial origin. The rarity of uterine sarcomas and their aggressive clinical course has resulted in a relatively limited amount of literature. Total abdominal hysterectomy and bilateral salpingo-oophorectomy remains the standard surgical care. 
Lymph node dissection is indicated for carcinosarcomas given their high incidence of lymph node metastases. Some recent data on small numbers of patients with lowgrade endometrial stromal sarcomas appear to show an incidence of nodal involvement higher than previously expected, thus suggesting a role for lymphadenectomy. Adjuvant pelvic radiotherapy appears to improve local control without any significant impact on overall survival. Regarding adjuvant chemotherapy, there is little evidence in the literature supporting its use except for carcinosarcomas. However, more trials are needed to address these issues, especially, their sequential application. Based on some recent, albeit limited data, combinations such as paclitaxel and carboplatin in carcinosarcomas, as well as gemcitabine and docetaxel in leiomyosarcomas merit further evaluation in prospective trials of adjuvant treatment.

\section{Abbreviations}

CIM: cisplatin-ifosfamide and mesna; CS: carcinosarcoma; CyVADIC: cyclophosphamide, vincristine, doxorubicin and dacarbazine; ER: estrogen receptor; ESS: endometrial stromal sarcoma; GOG: Gynecologic Oncology Group; LMS: leiomyosarcoma; PR: progesterone receptor; SEER: surveillance, epidemiology, and end results program; STS: soft tissue sarcoma; UUS: undifferentiated uterine sarcoma; VAC: vincristine, dactinomycin and cyclophosphamide; WAI: whole abdominal irradiation.

\section{Competing interests}

The authors declare that they have no competing interests.

\section{Authors' contributions}

FZ was involved in the writing of the manuscript (chemotherapy section), review of the literature, revised the manuscript. AMD revised the manuscript critically for important intellectual content. SF was involved in the writing of the manuscript (surgical treatment section), review of the literature. VK was involved in the writing of the manuscript (radiation therapy section), review of the literature. CAP was involved in conception of the idea, revised the manuscript critically for important intellectual content, final approval of the version to be published.

\section{References}

I. Salazar OM, Bonfiglio TA, Patten SF, Keller BE, Feldstein M, Dunne $M E$, Rudolph J: Uterine sarcomas: natural history, treatment and prognosis. Cancer 1978, 42: I I52-60.

2. Nordal RR, Thoresen SO: Uterine sarcomas in Norway 1956 1992: incidence, survival and mortality. Eur J Cancer 1997, 33:907-II.

3. Harlow BL, Weiss NS, Lofton S: The epidemiology of sarcomas of the uterus. I Natl Cancer Inst 1986, 76:399-402.

4. Papadimitriou CA, Zorzou MP, Markaki S, Rodolakis A, Voulgaris Z, Bozas G, Kastritis E, Bamias A, Gika D, Dimopoulos MA: Anthracycline-based adjuvant chemotherapy in early-stage uterine sarcomas: long-term results of a single institution experience. Eur J Gynaecol Oncol 2007, 28:109-16.

5. Jonson AL, Bliss RL, Truskinovsky A, Judson P, Argenta P, Carson L, Dusenbery K, Downs LS Jr: Clinical features and outcomes of uterine and ovarian carcinosarcoma. Gynecol Oncol 2006, 100:56I-4.
6. Berchuck A, Rubin SC, Hoskins WJ, Saigo PE, Pierce VK, Lewis JL Jr: Treatment of uterine leiomyosarcoma. Obstet Gynecol 1988, 71:845-50.

7. Berchuck A, Rubin SC, Hoskins WJ, Saigo PE, Pierce VK, Lewis JL Jr: Treatment of endometrial stromal tumors. Gynecol Oncol 1990, 36:60-5.

8. Kempson RL, Bari W: Uterine sarcomas. Classification, diagnosis, and prognosis. Hum Pathol 1970, I:331-49.

9. Brooks SE, Zhan M, Cote T, Baquet CR: Surveillance, epidemiology, and end results analysis of 2677 cases of uterine sarcoma 1989-1 999. Gynecol Oncol 2004, 93:204-8.

10. Ali S, Wells M: Mixed Mullerian tumors of the uterine corpus: a review. Int J Gynecol Cancer I993, 3: I- I I.

II. Iwasa $Y$, Haga H, Konishi I, Kobashi Y, Higuchi K, Katsuyama E, Minamiguchi S, Yamabe H: Prognostic factors in uterine carcinosarcoma: a clinicopathologic study of $\mathbf{2 5}$ patients. Cancer 1998, 82:512-9.

12. Ramondetta L, Bodurka D, Deavers M, Jhingran A: Uterine Sarcomas. In M. D. Anderson Cancer Care Series, Gynecologic Cancer Edited by: Eifel PJ, Gershenson DM, Kavanagh J], Silva EG. Springer. New York; 2006: 1 25-147.

13. Gadducci A, Cosio S, Romanini A, Genazzani AR: The management of patients with uterine sarcoma: a debated clinical challenge. Crit Rev Oncol Hematol 2008, 65: 129-42.

14. Zelmanowicz A, Hildesheim A, Sherman ME, Sturgeon SR, Kurman RJ, Barrett RJ, Berman ML, Mortel R, Twiggs LB, Wilbanks GD, Brinton LA: Evidence for a common etiology for endometrial carcinomas and malignant mixed mullerian tumors. Gynecol Oncol 1998, 69:253-7.

15. McCluggage WG: Uterine carcinosarcomas (malignant mixed Mullerian tumors) are metaplastic carcinomas. Int J Gynecol Cancer 2002, I 2:687-90.

16. Vrzic-Petronijevic S, Likic-Ladjevic I, Petronijevic M, Argirovic R, Ladjevic N: Diagnosis and surgical therapy of uterine sarcoma. Acta Chir lugosl 2006, 53:67-72.

17. Benoit L, Arnould L, Cheynel N, Goui S, Collin F, Fraisse J, Cuisenier $\mathrm{J}$ : The role of surgery and treatment trends in uterine sarcoma. Eur J Surg Oncol 2005, 31 : 434-42.

18. Major FJ, Blessing JA, Silverberg SG, Morrow CP, Creasman WT, Currie JL, Yordan E, Brady MF: Prognostic factors in early-stage uterine sarcoma. A Gynecologic Oncology Group study. Cancer 1993, 7 I(4 Suppl): I 702-9.

19. Kanjeekal S, Chambers A, Fung MF, Verma S: Systemic therapy for advanced uterine sarcoma: a systematic review of the literature. Gynecol Oncol 2005, 97:624-37.

20. Akahira J, Tokunaga H, Toyoshima M, Takano T, Nagase S, Yoshinaga K, Tase T, Wada Y, Ito K, Niikura H, Yamada H, Sato A, Sasano H, Yaegashi N: Prognoses and prognostic factors of carcinosarcoma, endometrial stromal sarcoma and uterine leiomyosarcoma: a comparison with uterine endometrial adenocarcinoma. Oncology 2006, 71:333-40.

21. Chauveinc L, Deniaud E, Plancher C, Sastre X, Amsani F, de la Rochefordiere $A$, Rozemberg $H$, Clough KB: Uterine sarcomas: the Curie Institut experience. Prognosis factors and adjuvant treatments. Gynecol Oncol 1999, 72:232-7.

22. Vaidya AP, Horowitz NS, Oliva E, Halpern EF, Duska LR: Uterine malignant mixed mullerian tumors should not be included in studies of endometrial carcinoma. Gynecol Oncol 2006, 1 03:684-7.

23. El Husseiny G, Al Bareedy N, Mourad WA, Mohamed G, Shoukri M, Subhi J, Ezzat A: Prognostic factors and treatment modalities in uterine sarcoma. Am J Clin Oncol 2002, 25:256-60.

24. Kokawa K, Nishiyama K, Ikeuchi M, Ihara Y, Akamatsu N, Enomoto T, Ishiko O, Motoyama S, Fujii S, Umesaki N: Clinical outcomes of uterine sarcomas: results from 14 years worth of experience in the Kinki district in Japan (1990-2003). Int J Gynecol Cancer 2006, 16:1358-63.

25. Temkin SM, Hellmann M, Lee YC, Abulafia O: Early-stage carcinosarcoma of the uterus: the significance of lymph node count. Int I Gynecol Cancer 2007, I 7:2 I 5-9.

26. Nemani D, Mitra N, Guo M, Lin L: Assessing the effects of lymphadenectomy and radiation therapy in patients with uterine carcinosarcoma: A SEER analysis. Gynecol Oncol 2008 in press.

27. Reed NS: The management of uterine sarcomas. Clin Oncol ( $R$ Coll Radiol) 2008, 20:470-8. 
28. Hornback NB, Omura G, Major FJ: Observations on the use of adjuvant radiation therapy in patients with stage I and II uterine sarcoma. Int J Radiat Oncol Biol Phys 1986, 12:2 I 27-30.

29. Dusenbery KE, Potish RA, Argenta PA, Judson PL: On the apparent failure of adjuvant pelvic radiotherapy to improve survival for women with uterine sarcomas confined to the uterus. Am J Clin Oncol 2005, 28:295-300.

30. Wright JD, Seshan VE, Shah M, Schiff PB, Burke WM, Cohen CJ, Herzog T]: The role of radiation in improving survival for earlystage carcinosarcoma and leiomyosarcoma. Am J Obstet Gynecol 2008 in press.

31. Callister M, Ramondetta LM, Jhingran A, Burke TW, Eifel PJ: Malignant mixed Müllerian tumors of the uterus: analysis of patterns of failure, prognostic factors, and treatment outcome. Int J Radiat Oncol Biol Phys 2004, 58:786-96.

32. Clayton Smith D, Kenneth Macdonald O, Gaffney DK: The impact of adjuvant radiation therapy on survival in women with uterine carcinosarcoma. Radiother Oncol 2008, 88:227-32.

33. Wolfson AH, Brady MF, Rocereto T, Mannel RS, Lee YC, Futoran RJ, Cohn DE, loffe OB: A gynecologic oncology group randomized phase III trial of whole abdominal irradiation (WAI) vs. cisplatin-ifosfamide and mesna (CIM) as post-surgical therapy in stage I-IV carcinosarcoma (CS) of the uterus. Gynecol Oncol 2007, 107:177-85.

34. Reed NS, Mangioni C, Malmström H, Scarfone G, Poveda A, Pecorelli S, Tateo S, Franchi M, Jobsen J], Coens C, Teodorovic I, Vergote I, Vermorken JB, European Organisation for Research and Treatment of Cancer Gynaecological Cancer Group: Phase III randomised study to evaluate the role of adjuvant pelvic radiotherapy in the treatment of uterine sarcomas stages I and II: an European Organisation for Research and Treatment of Cancer Gynaecological Cancer Group Study (protocol 55874). Eur J Cancer 2008, 44:808-18.

35. Sutton G, Kauderer J, Carson LF, Lentz SS, Whitney CW, Gallion H, Gynecologic Oncology Group: Adjuvant ifosfamide and cisplatin in patients with completely resected stage I or II carcinosarcomas (mixed mesodermal tumors) of the uterus: a Gynecologic Oncology Group study. Gynecol Oncol 2005, 96:630-4.

36. Makker V, Abu-Rustum NR, Alektiar KM, Aghajanian CA, Zhou Q, lasonos A, Hensley M: A retrospective assessment of outcomes of chemotherapy-based versus radiation-only adjuvant treatment for completely resected stage I-IV uterine carcinosarcoma. Gynecol Oncol 2008, I I I:249-54.

37. Cicin I, Saip P, Eralp Y, Selam M, Topuz S, Ozluk Y, Aydin Y, Topuz E: Ovarian carcinosarcomas: clinicopathological prognostic factors and evaluation of chemotherapy regimens containing platinum. Gynecol Oncol 2008, 108:136-40.

38. Wilkinson N, Rollason TP: Recent advances in the pathology of smooth muscle tumours of the uterus. Histopathology 200I, 39:33I-4I.

39. Zaloudek C, Hendrickson MR: Mesenchymal tumors of the uterus. In Blaustein's pathology of the female genital tract Edited by: Kurman RJ. New York: Springer-Verlag, Inc; 2002:56I-6I 5.

40. Leibsohn S, d'Ablaing G, Mishell DR Jr, Schlaerth JB: Leiomyosarcoma in a series of hysterectomies performed for presumed uterine leiomyomas. Am J Obstet Gynecol 1990, 162:968-74. discussion 974-6.

41. Akhan SE, Yavuz E, Tecer A, lyibozkurt CA, Topuz S, Tuzlali S, Bengisu $E$, Berkman S: The expression of Ki-67, p53, estrogen and progesterone receptors affecting survival in uterine leiomyosarcomas. A clinicopathologic study. Gynecol Oncol 2005, 99:36-42.

42. Leitao MM, Soslow RA, Nonaka D, Olshen AB, Aghajanian C, Sabbatini P, Dupont J, Hensley M, Sonoda Y, Barakat RR, Anderson S: Tissue microarray immunohistochemical expression of estrogen, progesterone, and androgen receptors in uterine leiomyomata and leiomyosarcoma. Cancer 2004, 10 I: | 455-62.

43. Gadducci A, Landoni F, Sartori E, Zola P, Maggino T, Lissoni A, Bazzurini L, Arisio R, Romagnolo C, Cristofani R: Uterine leiomyosarcoma: analysis of treatment failures and survival. Gynecol Oncol 1996, 62:25-32.

44. Giuntoli RL 2nd, Metzinger DS, DiMarco CS, Cha SS, Sloan JA, Keeney GL, Gostout BS: Retrospective review of 208 patients with leiomyosarcoma of the uterus: prognostic indicators, surgical management, and adjuvant therapy. Gynecol Oncol 2003, 89:460-9.
45. Gard GB, Mulvany NJ, Quinn MA: Management of uterine leiomyosarcoma in Australia. Aust N Z J Obstet Gynaecol 1999, 39:93-8.

46. Bodner K, Bodner-Adler B, Kimberger O, Czerwenka K, Leodolter S, Mayerhofer K: Evaluating prognostic parameters in women with uterine leiomyosarcoma. A clinicopathologic study. J Reprod Med 2003, 48:95-100.

47. Cantisani V, Mortele KJ, Kalantari BN, Glickman JN, Tempany C, Silverman SG: Vaginal metastasis from uterine leiomyosarcoma. Magnetic resonance imaging features with pathological correlation. J Comput Assist Tomogr 2003, 27:805-9.

48. Eloy JA, Mortensen M, Gupta S, Lewis MS, Brett EM, Genden EM: Metastasis of uterine leiomyosarcoma to the thyroid gland: case report and review of the literature. Thyroid 2007 , I7:| 295-7.

49. Elhammady MS, Manzano GR, Lebwohl N, Levi AD: Leiomyosarcoma metastases to the spine. Case series and review of the literature. I Neurosurg Spine 2007, 6: I78-83.

50. Hensley ML, Ishill N, Soslow R, Larkin J, Abu-Rustum N, Sabbatini P, Konner J, Tew W, Spriggs D, Aghajanian CA: Adjuvant gemcitabine plus docetaxel for completely resected stages I-IV high grade uterine leiomyosarcoma: Results of a prospective study. Gynecol Oncol 2009, I I 2:563-7.

5I. Diesing D, Cordes T, Finas D, Löning M, Mayer K, Diedrich K, Friedrich M: Endometrial stromal sarcomas - a retrospective analysis of I I patients. Anticancer Res 2006, 26:655-6I

52. Gadducci A, Sartori E, Landoni F, Zola P, Maggino T, Urgesi A, Lissoni A, Losa G, Fanucchi A: Endometrial stromal sarcoma: analysis of treatment failures and survival. Gynecol Oncol 1996, 63:247-53.

53. Oláh KS, Gee H, Blunt S, Dunn JA, Kelly K, Chan KK: Retrospective analysis of 318 cases of uterine sarcoma. Eur J Cancer I991, 27:1095-9.

54. Li N, Wu LY, Zhang HT, An JS, Li XG, Ma SK: Treatment options in stage I endometrial stromal sarcoma: a retrospective analysis of 53 cases. Gynecol Oncol 2008, 108:306-II.

55. Amant F, Vergote I, Moerman P. The classification of a uterine sarcoma as 'high-grade endometrial stromal sarcoma' should be abandoned. Gynecol Oncol 2004, 95:4I2-3. author reply 413 .

56. Chang KL, Crabtree GS, Lim-Tan SK, Kempson RL, Hendrickson MR: Primary uterine endometrial stromal neoplasms. A clinicopathologic study of II 7 cases. Am J Surg Pathol 1990, I 4:4 I5-38.

57. Kim L, Choi SJ, Park IS, Han JY, Kim JM, Chu YC, Kim KR: Endometrial stromal sarcoma of the small bowel. Ann Diagn Pathol 2008, I2:128-33.

58. Kurihara S, Oda Y, Ohishi Y, Iwasa A, Takahira T, Kaneki E, Kobayashi $\mathrm{H}$, Wake N, Tsuneyoshi M: Endometrial stromal sarcomas and related high-grade sarcomas: immunohistochemical and molecular genetic study of 3 I cases. Am J Surg Pathol 2008, 32:1228-38.

59. Balleine RL, Earls PJ, Webster LR, Mote PA, deFazio A, Harnett PR, Clarke $\mathrm{CL}$ : Expression of progesterone receptor $\mathbf{A}$ and $\mathbf{B}$ isoforms in low-grade endometrial stromal sarcoma. Int J Gynecol Pathol 2004, 23:138-44.

60. Al-Salam S, El-Terifi H, Ghazal-Aswad S: Low-grade endometrial stromal sarcoma with sex cord-like differentiation metastatic to the thoracic spines. APMIS 2006, I | 4:65 I-5.

61. Moinfar F, Regitnig P, Tabrizi AD, Denk H, Tavassoli FA: Expression of androgen receptors in benign and malignant endometrial stromal neoplasms. Virchows Arch 2004, 444:410-4.

62. Chu MC, Mor G, Lim C, Zheng W, Parkash V, Schwartz PE: Lowgrade endometrial stromal sarcoma: hormonal aspects. Gynecol Oncol 2003, 90:170-6.

63. Reich O, Regauer S, UrdI W, Lahousen M, Winter R: Expression of oestrogen and progesterone receptors in low-grade endometrial stromal sarcomas. Br J Cancer 2000, 82:1030-4.

64. Navarro D, Cabrera JJ, León L, Chirino R, Fernández L, López A, Rivero JF, Fernández P, Falcón O, Jiménez $P$, et al.: Endometrial stromal sarcoma expression of estrogen receptors, progesterone receptors and estrogen-induced srp27 (24 K) suggests hormone responsiveness. I Steroid Biochem Mol Biol 1992, 41:589-96.

65. Sabini G, Chumas JC, Mann WJ: Steroid hormone receptors in endometrial stromal sarcomas. $A$ biochemical and immunohistochemical study. Am J Clin Pathol 1992, 97:38I-6. 
66. Kir G, Cetiner H, Karateke A, Gurbuz A, Bulbul D: Utility of MIB$I$ and estrogen and progesterone receptor in distinguishing between endometrial stromal sarcomas and endometrial stromal nodules, highly cellular leiomyomas. Int J Gynecol Cancer 2005, 15:337-42.

67. Zhu XQ, Shi YF, Cheng XD, Zhao CL, Wu YZ: Immunohistochemical markers in differential diagnosis of endometrial stromal sarcoma and cellular leiomyoma. Gynecol Oncol 2004, 92:7I-9.

68. Popiolek D, Yee H, Levine P, Vamvakas E, Demopoulos RI: MIB I as a possible predictor of recurrence in low-grade endometrial stromal sarcoma of the uterus. Gynecol Oncol 2003, 90:353-7.

69. Weitmann HD, Kucera H, Knocke TH, Pötter R: Surgery and adjuvant radiation therapy of endometrial stromal sarcoma. Wien Klin Wochenschr 2002, II 4:44-9.

70. Weitmann HD, Knocke TH, Kucera H, Pötter R: Radiation therapy in the treatment of endometrial stromal sarcoma. Int J Radiat Oncol Biol Phys 200I, 49:739-48.

7I. Riopel J, Plante M, Renaud MC, Roy M, Têtu B: Lymph node metastases in low-grade endometrial stromal sarcoma. Gynecol Oncol 2005, 96:402-6.

72. Reich O, Winter R, Regauer S: Should lymphadenectomy be performed in patients with endometrial stromal sarcoma? Gynecol Oncol 2005, 97:982-3.

73. Pink D, Lindner T, Mrozek A, Kretzschmar A, Thuss-Patience PC, Dörken B, Reichardt P: Harm or benefit of hormonal treatment in metastatic low-grade endometrial stromal sarcoma: single center experience with 10 cases and review of the literature. Gynecol Oncol 2006, I 01 :464-9.

74. Berceanu S, Pătraşcu A, Berceanu C, Tica AA, Bădulescu A: Endometrial stromal sarcoma: clinico-pathological report of four cases and review of the literature. Rom J Morphol Embryol 2008, 49:25I-5.

75. Ihnen M, Mahner S, Jänicke F, Schwarz J: Current treatment options in uterine endometrial stromal sarcoma: report of a case and review of the literature. Int J Gynecol Cancer 2007, 17:957-63.

76. Ishiko O, Wakasa K, Honda K, Nakajima S, Ogita S: Excellent results of postoperative radiotherapy for endometrial stromal sarcoma of low-grade malignancy. Gynecol Obstet Invest 2000, 49:2 14-6.

77. Livi L, Andreopoulou E, Shah N, Paiar F, Blake P, Judson I, Harmer C: Treatment of uterine sarcoma at the Royal Marsden Hospital from 1974 to 1998. Clin Oncol (R Coll Radiol) 2004, 16:26I-8.

78. Reich $O$, Regauer S: Hormonal therapy of endometrial stromal sarcoma. Curr Opin Oncol 2007, 19:347-52.

79. Schindler AE, Campagnoli C, Druckmann R, Huber J, Pasqualini JR, Schweppe KW, Thijssen JH: Classification and pharmacology of progestins. Maturitas 2003, 46(Suppl I):S7-SI6.

80. Maluf FC, Sabbatini P, Schwartz L, Xia J, Aghajanian C: Endometrial stromal sarcoma: objective response to letrozole. Gynecol Oncol 200I, 82:384-388

81. Spano JP, Soria JC, Kambouchner M, Piperno-Neuman S, Morin F, Morere JF, Martin A, Breau JL: Long-term survival of patients given hormonal therapy for metastatic endometrial stromal sarcoma. Med Oncol 2003, 20:87-93.

82. Leunen M, Breugelmans M, De Sutter P, Bourgain C, Amy JJ: Lowgrade endometrial stromal sarcoma treated with the aromatase inhibitor letrozole. Gynecol Oncol 2004, 95:769-77I.

83. Leiser AL, Hamid AM, Blanchard R: Recurrence of prolactin-producing endometrial stromal sarcoma with sex-cord stromal component treated with progestin and aromatase inhibitor. Gynecol Oncol 2004, 94:567-57I.

84. Scribner DR Jr, Walker JL: Low-grade endometrial stromal sarcoma preoperative treatment with Depo-Lupron and Megace. Gynecol Oncol 1998, 7 I:458-460

85. Mesia AF, Demopoulos RI: Effects of leuprolide acetate on lowgrade endometrial stromal sarcoma. Am J Obstet Gynecol 2000, 182:1|40-II4I.

86. Burke C, Hickey K: Treatment of endometrial stromal sarcoma with a gonadotropin-releasing hormone analogue. Obstet Gynecol 2004, 1 04: I 182-1 I 84.

87. Reich O, Regauer S: Estrogen replacement therapy and tamoxifen are contraindicated in patients with endometrial stromal sarcoma. Gynecol Oncol 2006, 102:4|3-4|4.
88. De Fusco PA, Gaffey TA, Malkasian GD Jr, Long HJ, Cha SS: Endometrial stromal sarcoma: review of Mayo Clinic experience, 1945-1980. Gynecol Oncol 1989, 35:8-14.

89. Bramwell V, Rouesse J, Steward W, Santoro A, Schraffordt-Koops H, Buesa J, Ruka W, Priario J, Wagener T, Burgers M, et al.: Adjuvant CYVADIC chemotherapy for adult soft tissue sarcoma reduced local recurrence but no improvement in survival: a study of the European Organization for Research and Treatment of Cancer Soft Tissue and Bone Sarcoma Group. J Clin Oncol 1994, 12: I I37-49.

90. Frustaci S, Gherlinzoni F, De Paoli A, Bonetti M, Azzarelli A, Comandone A, Olmi P, Buonadonna A, Pignatti G, Barbieri E, Apice G, Zmerly H, Serraino D, Picci P: Adjuvant chemotherapy for adult soft tissue sarcomas of the extremities and girdles: results of the Italian randomized cooperative trial. I Clin Oncol 200I, 19:1238-47.

91. Frustaci S, De Paoli A, Bidoli E, La Mura N, Berretta M, Buonadonna A, Boz G, Gherlinzoni F: Ifosfamide in the adjuvant therapy of soft tissue sarcomas. Oncology 2003, 65(Suppl 2):80-4.

92. Sarcoma Meta-Analysis Collaboration (SMAC): Adjuvant, chemotherapy for localised respectable soft tissue sarcoma in adults. Cohchrane Database Syst Rev 2000:CD00I4I9.

93. Hannigan EV, Freedman RS, Rutledge FN: Adjuvant chemotherapy in early uterine sarcoma. Gynecol Oncol 1983, 15:56-64.

94. Buchsbaum HJ, Lifshitz S, Blythe JG: Prophylactic chemotherapy in stages I and II uterine sarcoma. Gynecol Oncol 1979, 8:346-8.

95. van Nagell JR Jr, Hanson MB, Donaldson ES, Gallion HH: Adjuvant vincristine, dactinomycin, and cyclophosphamide therapy in stage I uterine sarcomas. A pilot study. Cancer 1986, 57:145I-4.

96. Hempling RE, Piver MS, Baker TR: Impact on progression-free survival of adjuvant cyclophosphamide, vincristine, doxorubicin (adriamycin), and dacarbazine (CYVADIC) chemotherapy for stage I uterine sarcoma. A prospective trial. Am J Clin Oncol 1995, 18:282-6.

97. Odunsi K, Moneke V, Tammela J, Ghamande S, Seago P, Driscoll D, Marchetti D, Baker T, Lele S: Efficacy of adjuvant CYVADIC chemotherapy in early-stage uterine sarcomas: results of long-term follow-up. Int ] Gynecol Cancer 2004, 14:659-64.

98. Kushner DM, Webster KD, Belinson JL, Rybicki LA, Kennedy AW, Markman M: Safety and efficacy of adjuvant single-agent ifosfamide in uterine sarcoma. Gynecol Oncol 2000, 78:22।-7.

99. Pautier P, Rey A, Haie-Meder C, Kerbrat P, Dutel JL, Gesta P, Bryard $F$, Morice $P$, Duvillard $P$, Lhommé C: Adjuvant chemotherapy with cisplatin, ifosfamide, and doxorubicin followed by radiotherapy in localized uterine sarcomas: results of a case-control study with radiotherapy alone. Int J Gynecol Cancer 2004, 14: I II 2-7.

100. Omura GA, Blessing JA, Major F, Lifshitz S, Ehrlich CE, Mangan C, Beecham J, Park R, Silverberg S: A randomized clinical trial of adjuvant adriamycin in uterine sarcomas: a Gynecologic Oncology Group Study. J Clin Oncol 1985, 3:1240-5.

10I. Resnik E, Chambers SK, Carcangiu ML, Kohorn El, Schwartz PE, Chambers JT: A phase II study of etoposide, cisplatin, and doxorubicin chemotherapy in mixed müllerian tumors (MMT) of the uterus. Gynecol Oncol 1995, 56:370-5.

102. Manolitsas TP, Wain GV, Williams KE, Freidlander M, Hacker NF: Multimodality therapy for patients with clinical Stage I and II malignant mixed Müllerian tumors of the uterus. Cancer 200 I, 91:1437-43.

103. Cassier PA, Dufresne A, Blay J-Y, Fayette J: Trabectedin and its potential in the treatment of soft tissue sarcoma. Ther Clin Risk Manag 2008, 4: 109-II6.

104. Wu TI, Chang TC, Hsueh S, Hsu KH, Chou HH, Huang HJ, Lai CH: Prognostic factors and impact of adjuvant chemotherapy for uterine leiomyosarcoma. Gynecol Oncol 2006, 100:166-72.

105. Piver MS, Lele SB, Marchetti DL, Emrich LJ: Effect of adjuvant chemotherapy on time to recurrence and survival of stage $I$ uterine sarcomas. J Surg Oncol 1988, 38:233-9.

106. Sartori E, Bazzurini L, Gadducci A, Landoni F, Lissoni A, Maggino T, Zola P, La Face B: Carcinosarcoma of the uterus: a clinicopathological multicenter CTF study. Gynecol Oncol 1997, 67:70-5 